\title{
Quality of life in multiple sclerosis in France, Germany, and the United Kingdom
} N Murphy, C Confavreux, J Haas, N König, E Roullet, M Sailer, M Swash, C Young,
the Cost of Multiple Sclerosis Study Group (see Appendix), and Mérot J-L
Rudick et al found that family life, economic status, and social interaction may be affected by the somatic symptoms of the disease. ${ }^{3}$ Compared with inflammatory bowel disease and rheumatoid arthritis, multiple sclerosis has the lowest QoL and medical problem ratings. Cognitive dysfunction that affects $43 \%$ to $65 \%$ of patients with multiple sclerosis also has a major negative influence on QoL; cognitively impaired patients are less likely to be professionally active, are more dependent, report more sexual dysfunction, and tend to be less socially engaged than cognitively intact patients with multiple sclerosis. ${ }^{4}$ These findings suggest that cognitive dysfunction is a major factor in determining the QoL of patients with multiple sclerosis. Health promoting behaviours have been recognised as important strategies in dealing with the lowered QoL associated with multiple sclerosis and other chronic diseases. ${ }^{5}$

The objective of the present study was not only to investigate the impact of multiple sclerosis on QoL, but also to compare QoL in these patients with control patients (patients presenting no evidence of multiple sclerosis). The 34 item functional status questionnaire $(\mathrm{FSQ})^{6}$ was selected as a means of evaluation. This questionnaire has been designed to screen for disability and to monitor clinically meaningful change. One of the advantages of the FSQ is that work related QoL is examined more comprehensively than in other generic instruments such as the SF-36. Translations of the FSQ exist in English, French, and German ${ }^{7}$ and this instrument has been validated across a range of diseases. ${ }^{8}$

Patients and methods

A cross sectional approach was adopted to collect QoL data at a single time point in France, Germany, and the United Kingdom. ${ }^{9}$

Kingdom; France; Germany; functional status questionnaire

Quintiles, 3-5 rue Maurice Ravel, 92594 Levallois Perret Cedex, France N Murphy

Correspondence to: Dr Nuala Murphy, Quintiles, 3-5 rue Maurice Ravel, 92594 Levallois Perret

Cedex, France. Fax 003141 277200 .

Received 3 September 1997 and in revised form 16 December 1997 Accepted 12 March 1998
It is generally recognised that multiple sclerosis can dramatically affect the quality of life (QoL) experienced by afflicted patients and their families. Many patients with multiple sclerosis have a normal life span and have to live with some degree of disability over a prolonged period. For this reason, evaluation of the impact of both pharmacological and nonpharmacological therapy should include an assessment of QoL. ${ }^{1}$ The overall concept of QoL encompasses various domains ${ }^{2}$ that can be assessed by using standardised generic questionnaires.

\section{PATIENTS}

Patients with multiple sclerosis were categorised into severity groups according to the expanded disability severity scale as assessed by the investigator (EDSS; stage I, 1.0-3.5; stage II, 4.0-6.0; stage III, 6.5-8.0). Patients, aged 18 and over, were included in the study if they had met the Poser committee diagnostic and gave informed consent. Patients excluded from the study were those (a) institutionalised at the time of observation, (b) those who had acute major comorbidities (any major respiratory, cardiovascular, gastrointestinal, renal, autoimmune, haematological, endocrine, criteria $^{10}$ for at least 3 months before inclusion 
Table 1 Baseline characteristics of multiple sclerosis (MS) and control patients

\begin{tabular}{|c|c|c|c|c|c|c|c|}
\hline & Stage I & Stage II & Stage III & $p$ Value & MS patients & Control & $p$ Value \\
\hline France $(\mathrm{n}):$ & 30 & 30 & 30 & & 90 & 30 & \\
\hline Age (y, mean (SD)) & $38.3(10.1)$ & $42.2(8.6)$ & $44.6(9.6)$ & $0.04 \ddagger$ & $41.7(9.7)$ & $42.0(9.2)$ & $0.87 \ddagger$ \\
\hline$\%$ Female & 70.0 & 66.7 & 60.0 & $0.71^{\star}$ & 65.6 & 66.7 & $0.91^{\star}$ \\
\hline Years since onset (mean (SD)) & $10.7(8.0)$ & $12.7(8.5)$ & $14.5(6.3)$ & $0.07 \S$ & $12.6(7.7)$ & NA & \\
\hline Clinically defined MS (n (\%)) patients & $27(93.3)$ & $30(100)$ & $29(96.7)$ & $0.77 \dagger$ & $87(96.6)$ & & \\
\hline Laboratory supported definite MS (n (\%)) & $2(6.7)$ & $0(0.0)$ & $1(3.3)$ & & $3(3.3)$ & & \\
\hline Germany (n): & 30 & 30 & 29 & & 89 & 30 & \\
\hline Age (y, mean (SD)) & $37.9(7.9)$ & $45.3(10.4)$ & $44.7(10.1)$ & $0.005 \ddagger$ & $42.6(10.0)$ & $43.1(11.2)$ & $0.98 \sqrt{0}$ \\
\hline$\%$ Female & 60.0 & 60.0 & 62.1 & $0.98^{\star}$ & 60.7 & 66.7 & $0.56^{\star}$ \\
\hline Years since onset (mean $(\mathrm{SD}))$ & $7.9(7.0$ & $12.1(7.3$ & $15.4(8.7$ & $0.001 \S$ & $11.8(8.2$ & NA & \\
\hline Clinically defined MS (n (\%)) patients & $29(96.7)$ & $30(100)$ & $28(96.5)$ & $0.77 \dagger$ & $87(97.8)$ & & \\
\hline Laboratory supported definite MS (n (\%)) patients & $1(3.3)$ & $0(0.0)$ & $1(3.4)$ & & $2(2.2)$ & & \\
\hline United Kingdom ( $\mathrm{n})$ : & 30 & 29 & 29 & & 88 & 30 & \\
\hline Age (y, mean (SD)) & $41.3(10.8)$ & $44.0(12.4)$ & $50.4(13.5)$ & $0.02 \ddagger$ & $45.2(12.7)$ & $45.0(12.2)$ & 0.928 \\
\hline$\%$ Female & 83.3 & 51.7 & 65.5 & $0.04^{\star}$ & 67.0 & 66.7 & $0.97^{\star}$ \\
\hline Years since onset (mean (SD)) & $11.6(8.9)$ & $13.4(10.3)$ & $18.9(10.9)$ & $0.03 \S$ & $14.6(10.4)$ & NA & \\
\hline Clinically defined MS (n (\%)) patients & $24(80)$ & $24(82.8)$ & $23(79.3)$ & $0.94 \dagger$ & $71(80.7)$ & & \\
\hline Laboratory supported definite MS (n (\%)) patients & $6(20.0)$ & $5(17.2)$ & $6(20.7)$ & & $17(19.3)$ & & \\
\hline
\end{tabular}

${ }^{\star} \chi^{2}$; $†$ Fisher exact test; $\ddagger$ Student $t$ test; $§ W i l c o x o n$ test.; $N A=$ not available

metabolic, neurological, or psychiatric disorders) or any major serious chronic illness (such as cancer or major psychiatric disorders) 3 months before inclusion (patients with a stable chronic medical condition were included), (c) patients with any neurological illness other than multiple sclerosis, and (d) those who had participated in any drug or non-drug related trial in the past 3 months.

A second group of patients - controls - were matched to the multiple sclerosis patients according to age and sex, and were included in the study if they had sought spontaneous consultation with their general practitioners but showed no evidence or suspicion of multiple sclerosis. Controls were excluded if (a) they were institutionalised, (b) if they had acute major comorbidities or any major chronic rheumatological, neurological, or psychiatric diseases (patients with a stable chronic medical condition were included), (c) or if they had

Table 2 International classification of diseases (ICD-9): control patients

\begin{tabular}{|c|c|c|c|}
\hline & \multicolumn{3}{|c|}{ Patients $(n)$ presenting disorders ${ }^{*}$} \\
\hline & $U K$ & France & Germany \\
\hline Symptoms, signs, and ill-defined conditions & 2 & 5 & 7 \\
\hline Infectious and parasitic disease & & & 2 \\
\hline Endocrine, nutritional, and metabolic disease & 3 & 4 & 5 \\
\hline Goitre & & & 3 \\
\hline Mental disorders & 6 & 5 & 2 \\
\hline Anxiety or depression & 5 & 5 & \\
\hline Disease of nervous system and sense organs & 2 & 4 & 4 \\
\hline Migraine & & 3 & 2 \\
\hline Diseases of the circulatory system & 3 & 3 & 7 \\
\hline Hypotension or hypertension & 3 & & 5 \\
\hline Venous insufficiency & & 2 & \\
\hline Diseases of the respiratory system & 14 & 5 & 6 \\
\hline Asthma & 5 & 3 & \\
\hline Chronic bronchitis or COPD & 3 & & \\
\hline Polynose & & & 4 \\
\hline Rhinitis or hayfever & 4 & 3 & \\
\hline Diseases of the digestive system & 5 & 3 & 9 \\
\hline $\begin{array}{l}\text { Functional or spasmodic cholic disorders } \\
\text { Proctitis or constipation }\end{array}$ & & 3 & 6 \\
\hline Diseases of the genitourinary sytem & 1 & 4 & 2 \\
\hline Menopause & & 2 & \\
\hline Disease of the skin and subcutaneous tissue & 6 & 3 & 3 \\
\hline Ezcema & 2 & 2 & \\
\hline Diseases of the mucoskeletal system and connective tissue & 8 & 5 & 11 \\
\hline Arthrosis & & & 4 \\
\hline Osteoarthritis or painful joints & 6 & & \\
\hline Osteoporosis & & & 3 \\
\hline Scoliosis & & 2 & \\
\hline
\end{tabular}

${ }^{\star}$ Results were expressed as the total number of patients presenting the principal classes (based on the ICD-9) and the disorder found most often within a given class. COPD=chronic obstructive airway disease. participated in any drug or non-drug related trial in the past 3 months.

DATA COLLECTION

In addition to the QoL data, sociodemographic data were collected on the day of inclusion as previously described. ${ }^{9}$

PROCEDURE

Patients with multiple sclerosis were recruited by neurologists in two centres in France (Hôpital Tenon, Paris; Hôpital de L'Antiquaille, Lyon), Germany (Otto von Guericke-Universität, Magdeburg; Judisches Krankenhaus, Berlin; Marianne-Strau $\beta$ Klinik, Milchberg), and the United Kingdom (Walton Centre for Neurology and Neurosurgery, Liverpool; Royal London Hospital, London). Control patients were independently recruited by general practitioners (GPs) in neighbouring local practices in two centres in France (Versailles, Lyon) and the United Kingdom (London; Liverpool) and three centres in Germany (Nittendorf; two centres in Berlin). The recruitment period for the study lasted 10 months. The target population of evaluable patients was 360 - that is, 90 patients with multiple sclerosis and 30 control patients for each country. Patients with multiple sclerosis were recruited from the established clinical practice in the 13 centres, either by means of random selection derived from a database list (Walton Centre, Liverpool) or on the basis of spontaneous consultations (all other centres), as were the controls. Subsequent to inclusion of patients with multiple sclerosis, GPs were informed of their age and sex. A consecutive series of control patients corresponding to the appropriate characteristics were included in the study, thus minimising recruitment bias.

Each patient completed the FSQ questionnaire (self completion) on the day of inclusion and before any consultation. Any bias that may be introduced by discussing the patients' health status and emotions before completion was therefore limited. All items in the questionnaire concern the 1 month interval before completion. Ethics committee approval was obtained before inclusion. 
ANALYSIS

For each scale and subscale, internal reliability was assessed using Cronbach's $\alpha$ for the entire population (all severity and control groups combined). The evaluation of the reliability of any measurement procedure consists of estimating how much of the variation in a score could represent chance or random errors. ${ }^{11}$ Cronbach's $\alpha$ ranges from 0 to 1 and 1 equals perfect reliability.

Item discriminant validity ${ }^{12}$ was tested by correlating the individual items with all scales in the questionnaire (each item of the FSQ was correlated with all scales of the FSQ). The discriminant validity of the questionnaire was tested by examination of the relation (correlation) between the individual subscales within the questionnaire. Concurrent validity was analysed by calculating the correlation between the scales and clinical measures (the EDSS).

The calculation of scores of the FSQ were transformed according to published algorithms. ${ }^{6}$ Two validated procedures were employed to
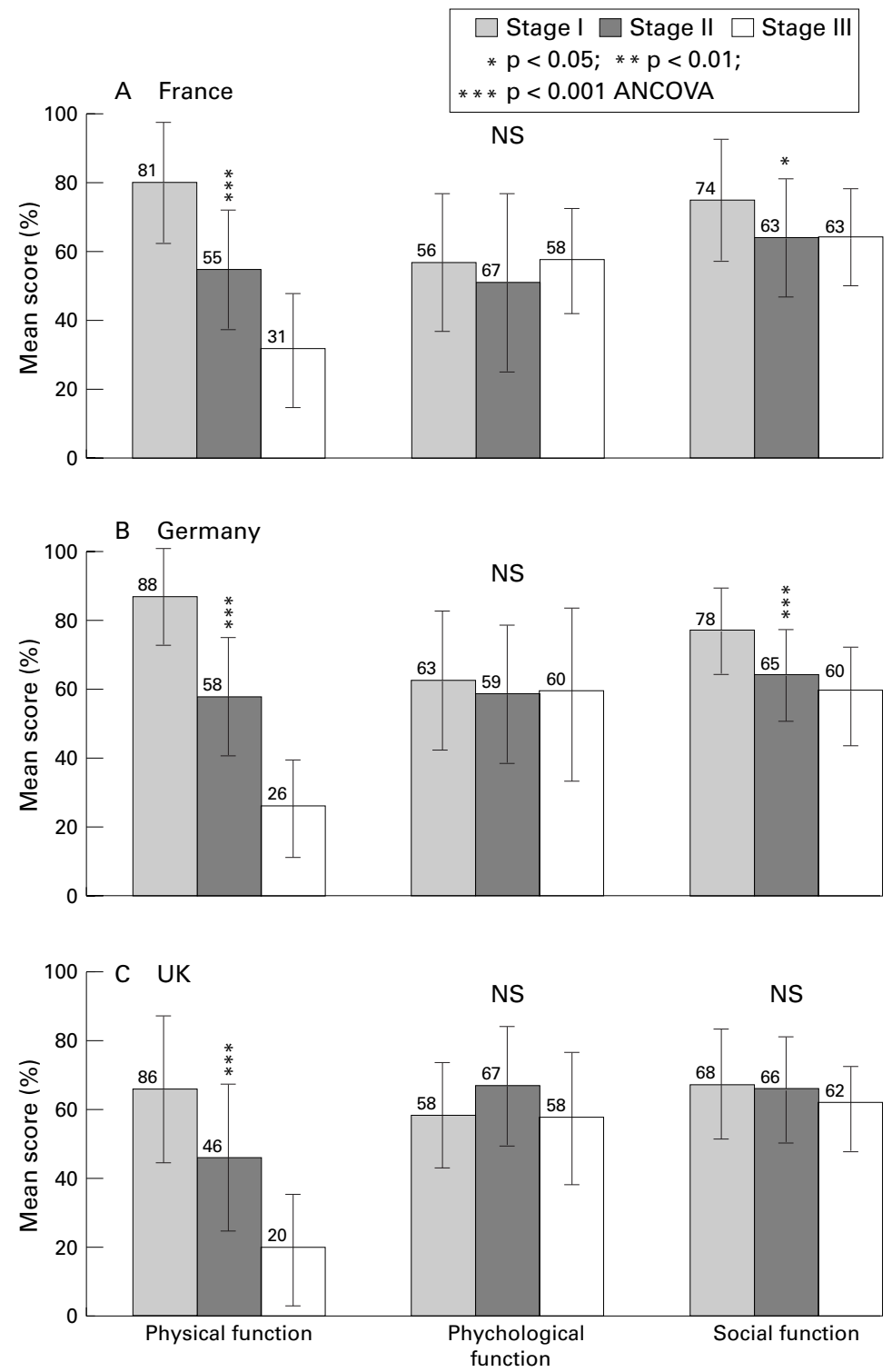

Figure 1 Main quality of life scores of patients with multiple sclerosis, measured by FSQ scores. limit the number of missing values and multiple answers. Missing values were substituted only when the respondent answered at least $50 \%$ of the items or half plus 0.5 in the case of scales with an odd number of items. The missing values (for a subscale) were replaced with the mean of the completed items in the same subscale. Previous work has shown that the average score across completed items in the same scale for that respondent is a psychometrically sound estimate. ${ }^{13}$ In the case of multiple answers for the same question, and if the answers were adjacent, one answer was randomly chosen. The same method was applied in the case of an answer lying between two adjacent options.

Quality of life, as measured by the FSQ, was expressed as the mean (SD) and the corresponding confidence interval. The scores between severity groups and all patients with multiple sclerosis together compared with the control group were compared using an ANCOVA analysis with age as a covariable. The relations between QoL scores and severity of disease were assessed by the Pearson correlation coefficient and its related confidence interval (CI). Because the sample size was low, the CI was estimated by the Pearson and Hartley method $^{14}$ (hyperbolic tangent argument transformation). Only results of the main scales (physical function, psychological function, and social function) have been presented in detail. When significant differences were seen for single item scales, results are referred to in the text.

\section{Results}

PATIENTS

Among the 270 patients with multiple sclerosis included in the study, two patients from the United Kingdom and one patient from Germany were excluded from the analysis as their EDSS rating was $>8.0$.

CHARACTERISTICS OF THE POPULATION

In the United Kingdom and France, increased severity was associated with increasing age; however, stage III patients in Germany were slightly younger than stage II patients (table $\left.1^{9}\right)$. In all three countries, a higher proportion of females than males was included in the study. The mean number of years since the onset of multiple sclerosis was highest for stage III patients in the United Kingdom. According to the Poser diagnostic criteria, most patients were diagnosed with clinically defined multiple sclerosis (table 1 ).

Control patients were classified according to the international classification of diseases (ICD-9). ${ }^{15}$ Diseases of the respiratory system (asthma, chronic bronchitis, or chronic obstructive pulmonary disease) and of the mucoskeletal system/connective tissue (arthrosis, osteoarthritis etc) were most often seen in the United Kingdom and Germany respectively (table 2). Ill defined conditions, mental disorders (anxiety and depression), respiratory and mucoskeletal/connective tissue disorders were among the disorders found most often in France. 

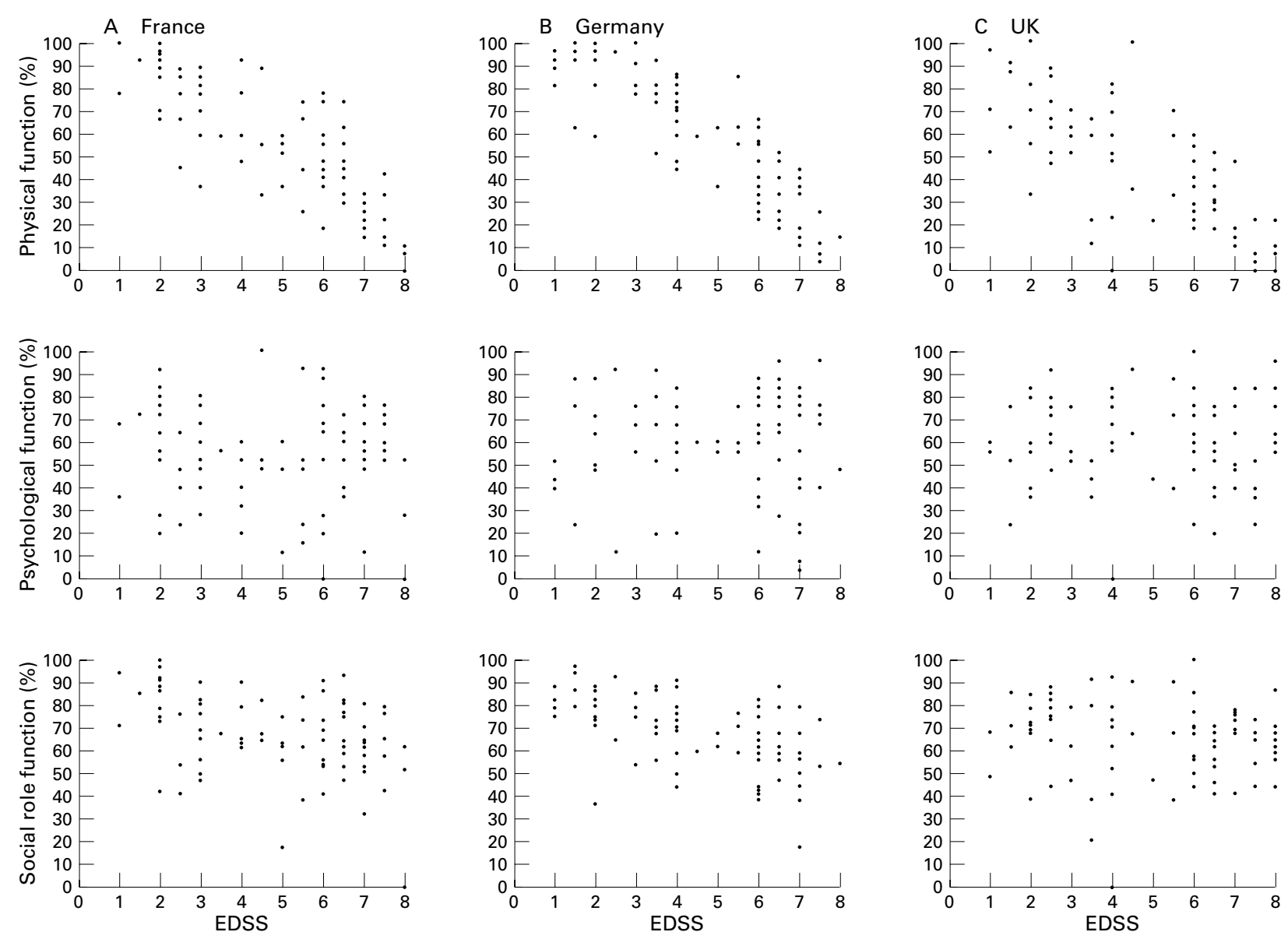

Figure 2 Main quality of life scores for patients with multiple sclerosis.

RELIABILITY AND VALIDITY

The reliabilities (Cronbach's $\alpha$ ) of the FSQ scales were all $>0.5$ both for patients with multiple sclerosis and control patients. Particularly high reliability was found for physical function ( $>0.9$ for all patients with multiple sclerosis in all countries; $>0.8$ for controls in the United Kingdom and Germany; 0.6 for controls in France) and psychological function ( $>0.8$ for patients with multiple sclerosis and control patients in France and Germany; $>0.6$ in the United Kingdom). The reliability of the social function scale was $>0.6$ for all patients with multiple sclerosis and control patients in all countries, with the exception of the inactive multiple sclerosis patient group in France (0.5).

Statistical analysis indicated correlation coefficients of either strong or substantial discriminant validity between main scales and subscales (results not shown).

\section{MAIN SCALES}

Physical function, which encompasses basic activities of daily living (for example, self care, walking indoors) and intermediate activities (for example, shopping, use of public transport, running, lifting heavy objects) significantly decreased with increased severity in each country (figs 1,2 ). Social role function encompasses work performance (for example, did the patient work as much as others in similar jobs, fear of losing a job, diminished work hours), social interaction (for example, isolation from others, irritation towards others, unreasonable demands, affection towards others) and social activity (for example, difficulty in visiting friends and relatives, participating in community activities, taking care of others). Comparison of social role function among the three severity groups indicated a disparity among the three countries. Whereas a significant difference was found among the three severity groups in France and more importantly in Germany, no significant difference was noted in the United Kingdom. However, when all patients with multiple sclerosis (all severity groups) were considered, the mean scores were the same for each country (table 3). Psychological function did not seem to vary significantly across severity groups in any of the three countries.

Comparison of the main scales (physical function, psychological function, social role function, and the single item scale general wellbeing; table 3) between all patients with multiple sclerosis and control patients showed a highly significant difference in all categories. Globally, the scores of physical function and general wellbeing for all patients with multiple sclerosis were between $40 \%$ and $50 \%$ lower than those of the the control group. By comparison, scores of psychological function and social role function obtained for all patients with multiple sclerosis were about $20 \%$ lower than in the control group. 
The single item scale general wellbeing (how the patient feels about his or her own health) diminished considerably from stage I to stage II, but to a lesser extent on progression to stage III and a significant difference among severity groups was found in the three countries (table 4). No significant difference was found among

Table 3 Quality of life of multiple sclerosis (MS) versus control patients

\begin{tabular}{|c|c|c|c|}
\hline & Variables & MS patients & Control \\
\hline \multicolumn{4}{|l|}{ France: } \\
\hline \multirow[t]{3}{*}{ Physical function } & Mean (SD) & $55.8(26.0)$ & $96.2(6.2)$ \\
\hline & $95 \% \mathrm{CI}$ & $50.4-61.2$ & $94.0-98.4$ \\
\hline & $\mathrm{n}$ & 89 & 30 \\
\hline \multirow[t]{3}{*}{ Psychological function } & Mean (SD) & $55.0(20.6)$ & $71.1(17.4)$ \\
\hline & $95 \%$ CI & $50.7-59.2$ & $64.9-77.3$ \\
\hline & $\mathrm{n}$ & 89 & 30 \\
\hline \multirow[t]{3}{*}{ Social role function } & Mean (SD) & $67.0(16.5)$ & $82.7(11.0)$ \\
\hline & $95 \% \mathrm{CI}$ & $63.6-70.4$ & $78.7-86.6$ \\
\hline & $\mathrm{n}$ & 89 & 30 \\
\hline \multirow[t]{3}{*}{ General wellbeing } & Mean (SD) & $31.3(29.1)$ & $77.1(14.6)$ \\
\hline & $95 \% \mathrm{CI}$ & $25.2-37.4$ & $71.2-82.9$ \\
\hline & $\mathrm{n}$ & 87 & 24 \\
\hline \multicolumn{4}{|l|}{ Germany: } \\
\hline \multirow[t]{3}{*}{ Physical function } & Mean (SD) & $57.5(29.3)$ & $94.8(10.2)$ \\
\hline & $95 \% \mathrm{CI}$ & $51.4-63.6$ & $91.2-98.5$ \\
\hline & $\mathrm{n}$ & 89 & 30 \\
\hline \multirow[t]{3}{*}{ Psychological function } & Mean (SD) & $60.4(22.1)$ & $77.2(14.5)$ \\
\hline & $95 \% \mathrm{CI}$ & $55.8-65.0$ & $72.0-82.4$ \\
\hline & $\mathrm{n}$ & 89 & 30 \\
\hline \multirow[t]{3}{*}{ Social role function } & Mean (SD) & $67.5(15.6)$ & $84.8(12.5)$ \\
\hline & $95 \% \mathrm{CI}$ & $64.3-70.8$ & $80.3-89.2$ \\
\hline & $\mathrm{n}$ & 89 & 30 \\
\hline \multirow[t]{3}{*}{ General wellbeing } & Mean (SD) & $41.5(29.1)$ & $72.3(22.9)$ \\
\hline & $95 \% \mathrm{CI}$ & $35.4-47.6$ & $63.8-80.8$ \\
\hline & $\mathrm{n}$ & 88 & 28 \\
\hline \multicolumn{4}{|l|}{ United Kingdom: } \\
\hline \multirow[t]{3}{*}{ Physical function } & Mean (SD) & $44.3(27.0)$ & $82.3(22.4)$ \\
\hline & $95 \% \mathrm{CI}$ & $38.6-50.0$ & $74.3-90.3$ \\
\hline & $\mathrm{n}$ & 86 & 30 \\
\hline \multirow[t]{3}{*}{ Psychological } & Mean (SD) & $60.9(17.5)$ & $74.5(17.8)$ \\
\hline & $95 \% \mathrm{CI}$ & $57.2-64.6$ & $68.2-80.9$ \\
\hline & $\mathrm{n}$ & 87 & 30 \\
\hline \multirow[t]{3}{*}{ Social role function } & Mean (SD) & $65.4(15.2)$ & $78.0(18.2)$ \\
\hline & $95 \% \mathrm{CI}$ & $62.2-68.6$ & $71.5-84.5$ \\
\hline & $\mathrm{n}$ & 87 & 30 \\
\hline \multirow[t]{3}{*}{ General wellbeing } & Mean (SD) & $34.2(27.5)$ & $62.0(22.3)$ \\
\hline & $95 \% \mathrm{CI}$ & $28.1-40.2$ & $53.6-70.5$ \\
\hline & $\mathrm{n}$ & 79 & 27 \\
\hline
\end{tabular}

$\mathrm{p} \leqslant 0.001$, analysis of covariance (ANCOVA) in all cases. severity groups for the other single item scales: days with restricted activities, days in bed, frequency of interaction, and sexual relationship (results not shown)

Review of the correlation coefficients provided insight into the disease characteristics that affect the QoL of patients with multiple sclerosis. As described in table 5, a significant correlation between severity of multiple sclerosis (as measured using the EDSS scale) and QoL was found for physical function and general wellbeing in the three countries and social role function in France and the United Kingdom (see above, no significant difference in social role function in the United Kingdom). No correlation was found between disease severity and psychological function.

\section{Discussion}

Diseases impact on family life in various ways. In addition to the alteration in the patient's professional life, multiple sclerosis may alter family life and economic status, ${ }^{5}$ consequences which will adversely influence the ultimate wellbeing or QoL of the patient. For example, in a previous study on the impact of multiple sclerosis on QoL, Hyman ${ }^{16}$ investigated the effects of social and psychological variables on the role performance of slightly ill ambulatory outpatients. Results indicated that certain kinds of self conceptions, social relationships, and attitudes toward illness were found to be associated with reductions of functioning in employment, household, and leisure activities after the onset of multiple sclerosis.

The assessment described in the present study is based on the patients' perception of QoL. Previous studies have indicated not only that doctors are not good at estimating the overall QoL of their patients, ${ }^{17}{ }^{18}$ but also that doctors' assessments of QoL differ from those

Table 4 Mean general wellbeing scores of controls and patients with multiple sclerosis (MS)

\begin{tabular}{|c|c|c|c|c|c|c|c|}
\hline & Stage I & Stage II & Stage III & $p$ Value & $\begin{array}{l}\text { Patients with } \\
M S\end{array}$ & Control & $p$ Value \\
\hline France $(\mathrm{n})$ & 30 & 29 & 28 & \multirow{5}{*}{$0.0036^{\star}$} & 87 & 24 & \multirow{4}{*}{$0.0001^{\star}$} \\
\hline Median & 50 & 25 & 25 & & 25 & 75 & \\
\hline Q1/Q3 & $0 / 75$ & $0 / 50$ & $0 / 25$ & & $0 / 50$ & $75 / 75$ & \\
\hline Min-max & $0-100$ & $0-100$ & $0-75$ & & $0-100$ & $50-100$ & \\
\hline Germany (n) & 30 & 29 & 29 & & 88 & 28 & \\
\hline Median & 75 & 25 & 25 & \multirow[t]{4}{*}{$0.0037^{\star}$} & 50 & 75 & \multirow[t]{3}{*}{$0.0001^{\star}$} \\
\hline Q1/Q3 & $25 / 75$ & $25 / 50$ & $0 / 50$ & & $25 / 75$ & $62.5 / 87.5$ & \\
\hline Min-max & $0-100$ & $0-100$ & $0-75$ & & $0-100$ & $25-100$ & \\
\hline United Kingdom (n) & 28 & 24 & 27 & & 79 & 27 & \\
\hline Median & 50 & 25 & 25 & \multirow[t]{3}{*}{$0.0111^{\star}$} & 25 & 75 & \multirow[t]{3}{*}{$0.0001^{\star}$} \\
\hline Q1/Q3 & $25 / 75$ & $0 / 50$ & $0 / 50$ & & $0 / 50$ & $50 / 75$ & \\
\hline Min-max & $0-75$ & $0-75$ & $0-75$ & & $0-75$ & $25-100$ & \\
\hline
\end{tabular}

*Wilcoxon test.

Table 5 Correlation between multiple sclerosis severity and QoL

\begin{tabular}{llll}
\hline Scales and subscales & France & Germany & UK \\
\hline Physical function: & $-0.83^{\star}$ & $-0.88^{\star}$ & $-0.77^{\star}$ \\
$\quad R$ & -0.62 to -0.29 & -0.92 to -0.82 & -0.85 to -0.67 \\
$\quad 95 \%$ CI & 0.01 & -0.04 & 0.035 \\
Psychological function or mental health: & -0.20 to 0.22 & -0.25 to 0.17 & -0.18 to 0.25 \\
$\quad R$ & $-0.36^{\star}$ & $-0.54^{\star}$ & -0.14 \\
$\quad 95 \%$ CI & -0.53 to -0.17 & -0.68 to -0.37 & -0.34 to 0.07 \\
$\begin{array}{l}\text { Social role function: } \\
\quad\end{array}$ & $-0.43^{\star}$ & $-0.38^{\star}$ & $-0.40^{\star}$ \\
$\quad 95 \%$ CI & -0.59 to -0.25 & -0.54 to -0.19 & -0.57 to -0.20 \\
$\quad \begin{array}{l}\text { General wellbeing: } \\
\quad 95 \% \text { CI }\end{array}$ &
\end{tabular}

*Pearson coefficient $R$ is significantly different from $0, \alpha=5 \%$. 
of patients ${ }^{19}$; doctors were more concerned about the physical aspects of multiple sclerosis, whereas patients were more concerned with mental health and vitality.

In the three countries under the present study, the aspects of QoL that were most affected were physical function and general wellbeing, all aspects that would be expected to be affected by a chronic disabling illness. Consequently, the patient has a tendency to become dependent on family, close friends, and community assistance. Indeed, such dependence was found in the present population, in that caregiving (family and friends) became an important component of the care of patients. ${ }^{9}$ Furthermore, the QoL of caregivers will also be affected, although such an assessment was not performed on the present population. The finding that general wellbeing diminished considerably from stage I to stage II, but to a lesser extent in stage III may suggest that the patient has come to terms with the disease.

These scales were not only diminished with increased severity but also compared with the control population. Rothwell et al ${ }^{19}$ similarly reported that physical functioning, physical role limitations, general health, and vitality were significantly diminished compared with a control population. This finding was based on patient perception of QoL assessed using the SF36. Contrary to the SF- $36,{ }^{20}$ the FSQ does not address the 4 item scale vitality (assessment of levels of energy); however the general health and physical scales are similar. Whereas some items are identical in text, others have similar meaning but different phrasing. Rothwell et $a l^{19}$ adopted a similar cross sectional approach comparing patients with multiple sclerosis with control patients matched according to age and sex characteristics.

In the present assessment social function, a function that involves activities which require physical effort, decreased with increased severity in France and in particular in Germany (a reduction in visits to friends or relatives, participation in community activities etc). On the contrary, such a decrease was not found for this scale in the United Kingdom. The disparities in each country may reflect differing management patterns of disability. ${ }^{9}$ Whereas psychological function did not seem to decrease with increased severity, it should be recognised that scores in this domain were significantly lower than in the control population.

Measurement of QoL may be used to supplement impairment scales, such as the EDSS. Whereas EDSS encompasses an evaluation of physical and cognitive deficits produced by multiple sclerosis, a QoL scale may reflect the impact of such an illness on the patients' life. In the present study, the generic FSQ questionnaire proved to be a relevant questionnaire owing to the discrimination found between patients with multiple sclerosis and control patients for each scale and also showed a significant decrease in physical function and general wellbeing with increased severity. The use of an instrument in a new disease from that in which it has been developed necessitates analysis of its psychometric properties. ${ }^{21}$ In the present assessment, high internal reliabilities of the questionnaire were found for each country, indicating that the FSQ scale could be said to be internally consistent and valid for multiple sclerosis. The use of this scale also allows comparison with scores in other diseases.

In conclusion, multiple sclerosis not only has an influence on the QoL of patients but, also, more severe disability is accompanied by a decrease in QoL. As scores found for all patients with multiple sclerosis were consistently lower than in control patients, multiple sclerosis may be considered to exert an impact on QoL. Any treatment resulting in a negative impact on the progression of multiple sclerosis may engender a slower deterioration in $\mathrm{QoL}$ and thus could be an important measure in clinical trials when assessing the benefit of a new therapy in clinical practice. Whereas such a cross sectional design has permitted an analysis of the QoL of patients with multiple sclerosis across severity groups and at one point in time, a cohort study could ideally be envisaged to investigate the rate of progression of QoL of patients with multiple sclerosis over time.

This research was supported by a grant from Biogen.

Appendix: The following institutions and investigators participated in the study Clinical Group - Multiple sclerosis recruitment centres: France; Lyon-Hôpital de l'Antiquaille, Service de NeurologieConfavreux C (local principal investigator), Moreau T, Cortinovis-Tourniare P; ParisHôpital Tenon, Service de NeurologieRoullet E (local principal investigator), Pez D; Germany; Berg-Marianne-Strau $\beta$-KlinikKönig N (local principal investigator), Basedow; Berlin; Judisches Krankenhaus- Haas J (local principal investigator), Zimmermann C; Magdeburg - Otto von Guericke-UniversitätSailer M (local principal investigator); UK: Liverpool-The Walton Centre for Neurology and Neurosurgery-Young C (local principal investigator), Owen L, Watling D; LondonRoyal London Hospital, Department of Neurology-Swash M (local principal investigator), Sharief $M$.

Control recruitment centres-France: Lyon-S Brohet, Versailles-Kanoui V; Germany: Berlin-Regling S; Nittendorf-Braun M; UK: Liverpool-Tewari VK, London-Bochsler JA.

Non-clinical group-France: Benefit International SNC-Murphy N, Mérot JL (coordinators), Auguin C, Kazek MP, Cook J, Tiffonet F, Yeardley $\mathrm{H}$.

1 Murray TJ. The psychological aspects of multiple sclerosis. Neurol Clin 1995;3:197-223.

Spilker B, ed. Quality of life and pharmacoeconomics in clinical trials. Philadephia: Lippincott-Raven.

3 Rudick RA, Miller D, Clough JD, et al. Quality of life in multiple sclerosis. Arch Neurol 1992;49:1237-42.

4 Rao SM, Leo GJ, Ellington L, et al. Cognitive dysfunction in multiple sclerosis. II Impact on employment and social multiple sclerosis. II Impact on emp

5 Stuifberger AK. Health promoting behaviours and quality of life among individuals with multiple sclerosis. Scholarly Inquiry for Nursing Practice: An International fournal Inquiry for N
1995;9:31-55. 
6 Jette AM, Davies AR, Cleary PD, et al. The functional status questionnaire: reliability and validity when used in primary care. Gen Intern Med 1986;1:143-9.

7 Monteban H, Hardens M, Vera M, et al. Quality of life measurement and the FSQ. Qual Life Res 1994;3:87.

8 Monteban $\mathrm{H}$, Hardens $M$, Vera $M$, et al. Validation of the functional status questionnaire in mental disorders. Qual Life Res 1994;3:87.

9 Murphy N, Confavreux C, Haas J, et al. Pharmacoeconomics 1998 (in press)

10 Poser CM, Paty DW, Scheinberg DH, et al. New diagnostic criteria for multiple sclerosis. Ann Neurol 1983;13:227-31.

11 Sellitz C, Wrightsman LS, Cook SW. Research methods in social relations. New York: Holt Rinehart and Winston, 1976:181.

12 Torrance GW. Measurement of health state utilities for economic appraisal. Fournal of Health Economics 1986;5:1-30.

13 Ware JE, Davies-Avery A, Brook RH. Conceptualization and measurement of health for adults in the health insurance study. Vol VI. Analysis of relationships among health status measures. Santa Monica, CA: RAND, 1980. (Publication R-1987/5HEW.)

14 Pearson ES, Hartley HO. Biometrika tables for statisticians. Vol I. Cambridge: University Press, 1966:264
15 Karaffa LA, ed. International classification of diseases, 9th revision. Clinical modification, 4 th ed. Vols 1,2 , and 3. California, US: 1993.

16 Hyman MD. Social psychological factors affecting disability among ambulatory patients. F Chron Dis 1975;28: 199-216.

17 Slevin ML, Plant H, Lynch D, et al. Who should measure the quality of life, the doctor or the patient? $\mathrm{Br} \mathcal{F}$ Cancer 1988;57:109-12.

18 Gerhart KA, Koziol-McLain J, Lowenstein SR, et al. Quality of life following spinal cord injury: knowledge and attitudes of emergency care providers. Ann Emerg Med 1994;23:807-12.

19 Rothwell PM, McDowell Z, Wong CK, et al. Doctors and patients don't agree: cross sectional study of patients' and doctors' perceptions and assessments of disability in multiple sclerosis. BMF 1997;314:1580-3.

20 Ware JE, Snow KK, Kosinski M, et al. SF-36 health survey-manual and interpretation guide. The Health Instisurvey-manual and interpretation guide.

21 Staquet M, Berzon R, Osoba D, et al. Guidelines for reporting results of quality of life assessments in clinical trials. Qual Life Res 1996;5:496-502. 